\title{
Bignoniaceae endémicas del Perú
}

\section{Arturo Granda}

Herbario del Departamento de Biología (MOL), Facultad de Ciencias, Universidad Nacional Agraria La Molina, Aptdo. 456, Lima, Perú. lamiaster@hotmail.com

\section{Resumen}

La familia Bignoniaceae es reconocida en el Perú por presentar 47 géneros y 166 especies (Brako \& Zarucchi, 1993), mayormente lianas y árboles. En este trabajo reconocemos cuatro especies endémicas, en igual número de géneros. Tres de estos endemismos ocupan las regiones Mesoandina y Matorral Desértico, entre los 300 y 4000 $\mathrm{m}$ de altitud, mientras que una especie es una liana de las regiones Bosques Muy Húmedos Premontanos y Bosques Secos. Ninguna de estas especies está representada en el Sistema Nacional de Áreas Naturales Protegidas por el Estado.

Palabras claves: Bignoniaceae, Perú, endemismo, plantas endémicas.

\section{Abstract}

The Bignoniaceae are represented in Peru by 47 genera and 166 species (Brako \& Zarucchi, 1993), basically lianas and trees. Here we recognize four endemic species in the same number of genera. Three of these endemics grow in Mesoandean and Desert Shrubland regions, between 300 and 4000 m elevation, while the fourth is a liana in Very Humid Premontane Forests and Dry Forests regions. None of the species have been collected to date within Peru's protected areas system.

Keywords: Bignoniaceae, Peru, endemism, endemic plants.

\section{Cuspidaria weberbaueri (Sprague) A.H. Gentry}

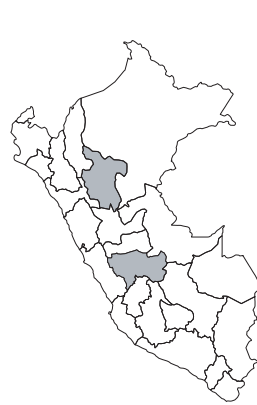

VU, B2ab(iii)

Publicación: Brittonia 25(3): 233. 1973. Colección tipo: A. Weberbauer 1934 Herbarios: G, K; MOL!

Nombre común: Desconocido.

Registro departamental: JU, SM.

Regiones Ecológicas: BS, BMHP; 300$1150 \mathrm{~m}$.

SINANPE: Sin registro.

Herbarios peruanos: MOL (isotipo), USM (4).

Observaciones: Liana conocida de sólo dos poblaciones, distantes aproximadamente $400 \mathrm{~km}$ una de otra. Ninguna población está registrada dentro de algún área protegida. Se aplica la categoría vulnerable, pues habita principalmente en valles con bosques secos aislados dentro de la zona de bosques montanos, los cuales se tornan frágiles por estar peligrosamente amenazados por la deforestación y una creciente colonización.

\section{Delostoma dentatum D. Don}

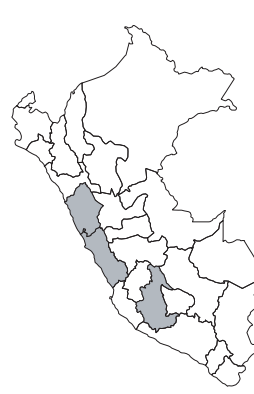

$$
\text { VU, B1ab(iii) }
$$

Publicación: Edinburgh Philos. J. 18: 263. 1823.

Colección tipo: J. Pavón 766

Herbarios: G.

Nombre común: Cara, carahuayta, carao Registro departamental: AN, AY, LI. Regiones Ecológicas: MDE, MA; 2000$3000 \mathrm{~m}$.

SINANPE: Sin registro.

Herbarios peruanos: MOL (3), USM (15).

Observaciones: Arbusto conocido de nueve poblaciones; la mayoría de las cuales provienen del Departamento de Lima; esto nos indica la frecuencia y continuidad de las exploraciones en dicha zona geográfica. Se halla en ambientes semixéricos con matorrales.

\section{Eccremocarpus huainaccapac Vargas}

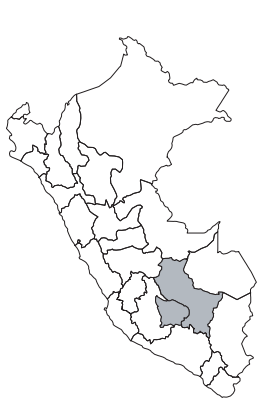

EN, B1ab(iii)

Publicación: Bol. Soc. Peruana Bot. 1:15. 1948. Colección tipo: C. Vargas C. 3034

Herbarios: K, US; $\underline{\mathrm{CUZ}}$.

Nombre común: Chucchucha $(\mathrm{CU})$.

Registro departamental: AP, CU.

Regiones Ecológicas: MA, PSH; 3165$4150 \mathrm{~m}$.

SINANPE: Sin registro.

Herbarios peruanos: CUZ (holotipo citado).

Observaciones: Bejuco conocido de un área aproximada de 2000 $\mathrm{km}^{2}$. Por la distancia entre las fechas de recolecta, 20 a 30 años entre una y otra, parece ser escasa en las localidades de recolecta o se necesitan más exploraciones en dichas áreas. No se ha registrado su presencia en ninguna unidad de conservación, pero dos localidades se hallan cerca del Santuario Nacional Ampay y del Santuario Histórico Machu Picchu respectivamente. En consecuencia, es probable su presencia dentro de dichas unidades.

\section{Tecoma guarume A. DC.}

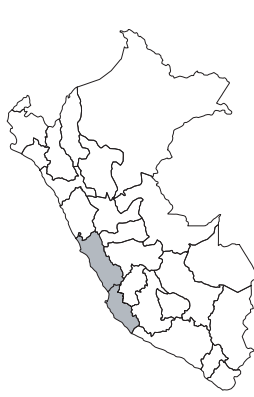

EN, B1ab(iii)

Publicación: Prodr. 9: 224-225. 1845.

Colección tipo: J. Pavón s.n.

Herbarios: $G$.

Nombre común: Cahuato.

Registro departamental: IC, LI.

Regiones Ecológicas: DST, MDE; 200$1200 \mathrm{~m}$.

SINANPE: Sin registro.

Herbarios peruanos: USM (12).

Observaciones: Arbusto conocido sólo de cinco poblaciones provenientes del Departamento de Ica. Las colecciones que representan esta especie son numerosas y se han dado a lo largo de los años. La especie es localmente frecuente y habita terrenos inmediatos a los ríos, formando parte de la vegetación de monte ribereño costero, generalmente cercana a terrenos de uso agrícola, carreteras o zonas pobladas. 